\title{
Power Quality Survey of Voltage Stabilizers and Uninterruptible Power Supply With Nonlinear Loads
}

\author{
Joel Ogunyemi and Zacchaeus A. Adetona
}

\begin{abstract}
Amongst the power quality problems faced in Nigeria, interruption and voltage fluctuation seem to be foremost. Thus, household electrical and electronic appliances are most times under the threat of outages and low voltage supply which cause them to malfunction or in extreme cases, get damaged. To address these problems, the use of uninterruptible power supply (UPS) and automatic voltage regulator commonly refer to as "stabilizer" has become very popular. The objective of this work is to examine the quality of these devices when powering other nonlinear devices. The experimental study was carried out by using a power harmonic analyzer to display the output parameters and waveform from each device under test when powering nonlinear loads. Parameters measured for each device were voltage, current, frequency, peak-to-peak voltage, total harmonic distortion (THD) and crest factor. The results showed that for the measured parameters, while other parameters relatively remain within the standards, the THD took an exemption as it was relatively higher with a range of 9.9 to $19.9 \%$ for various combination of loads. Though the outputs from the UPS were relatively higher than that of stabilizer (except for THD and crest factor where those of the stabilizer were higher), there was no significant difference between the parameter values measured. The implication of this was that increasing utilization of UPS and stabilizer will invariably continue to contribute more to the pollution of the existing weak network. Adequate measures were suggested to mitigate this. This research can be useful for the stakeholders in power industry for power quality improvement.
\end{abstract}

Index Terms - power quality, nonlinear loads, voltage stabilizer, uninterruptible power supply (UPS),

\section{INTRODUCTION}

The development of any country is largely hinged on the availability of quality and reliable power supply for sustainable economic diversification. Modern industrial and domestic consumers use an ever-increasing number of devices that primarily employ undisturbed and regulated power electronics based power-conditioners [1]. Nowadays, one of the major power quality concerns in electric power industry is the distortion of sinusoidal voltage and current waveforms caused by harmonics [2].

In Nigeria, apart from insufficient generation, the supply authority finds it difficult to actively maintain a steady voltage supply between the distribution point and the

Published on December 20, 2019.

J. Ogunyemi works with the Department of Electrical/Electronic Engineering, Federal Polytechnic, P.M.B.50, Ilaro

(e-mail: joel.ogunyemi@federalpolyilaro.edu.ng) consumer premises due to the variation of the drop in voltage as the connected loads vary. At the distribution final subcircuit, not less than $35 \%$ of the power available at this level is said to be lost due to wastage [3]. Therefore, the supply voltage from the ${ }^{1}$ supply authority is allowed to fluctuate between $\pm 6 \%$ of the declared nominal voltage under system stress or following system faults. Any voltage below or above this is termed under-voltage and over-voltage condition respectively.

The characteristics of voltage fluctuations depend on the load type, size and the power system capacity. There are two important parameters to voltage fluctuations namely the frequency of fluctuation and the magnitude of fluctuation. Both of these components are significant in the adverse effects of voltage fluctuations [4]. Voltage regulation is required for two distinct purposes: under-voltage and overvoltage conditions. Line voltage regulation is the process of maintaining constant output voltage to industrial and domestic users despite a wide variation in input voltage [5]. The two distinct reasons for voltage regulation aforementioned could be caused by abnormal forces of nature, atmospheric conditions, generator power surge, power grid defects, power distribution imbalance, etc. [6].

A nonlinear load (NLL) is defined by [7] as an electrical load which draws current discontinuously or whose impedance varies throughout the cycle of the input $\mathrm{AC}$ voltage waveform. In the steady state stability analysis and control design, the common approach is to assume sinusoidal conditions based on conditions in traditional power systems, where the amount of harmonics is usually negligible. Harmonics can lead to unpredicted interaction between components, which in worst case can lead to instability. To guarantee a stable network operation, the dynamic aspects of the harmonics have to be considered [8].

In Nigeria, there is continuous increase in load which is not balanced with continuous adequate upgrading of existing facilities or installation of new ones. Current load demand has overshot the load forecast of most substations [3]. There has been proliferation of different brands of commercial stabilizers in the Nigeria market with hundreds of thousands of stabilizers being imported into the country every year due to the power problem in Nigeria. Many of these stabilizers in Nigeria face situations beyond their design limit or

Z. A. Adetona works with the Department of Electrical/Electronic

Engineering, Federal Polytechnic, P.M.B.50, Ilaro, Nigeria.

(e-mail: zacchaeus.adetonai@federalpolyilaro.edu.ng)

*Corresponding author. 
specifications which render them vulnerable to poor power supply. Studies in the past revealed that $22 \%$ of stabilizers purchased by consumers were not performing satisfactorily as a result of very low input supply voltage [9]. In terms of operation, voltage stabilizer is a device that stabilizes voltage despite the variation in input. It prevents transients (high voltage spikes, etc.) from making it through to the delicate equipment connected to it. A UPS (Uninterruptible Power Supply), on the other hand, provides power (for a short period of time - often 15 minutes) when the main power source goes down.

The crest factor and the peak currents of a load are important considerations in power source selection. Crest factor is the ratio between the RMS value and the Peak value of the waveform and equal to 1.414. For a pure sinusoidal waveform shown in Fig. 1 the Crest Factor will always be given as:

$$
\text { Crest Factor }=\frac{\text { Peak Value }}{R M S \text { Value }}=\frac{V_{\max }}{0.707 \times V_{\max }}
$$

The total harmonic distortion (THD) of a power system is measured by power quality analyser. It is ratio of the root mean square of the harmonic content, considering harmonic components up to the 50th order and specifically excluding inter-harmonics, expressed as a percent of the fundamental. It is defined as the square root of the sum of the squares of amplitude of all harmonic voltages or current divided by the amplitude of the fundamental voltage or current, expressed in percent. Total harmonic voltage distortion (THDv) and Total harmonic current distortion (THDi) are the measure of distortion in the system. They are calculated as follows:

$$
\begin{gathered}
T H D_{V}=\frac{\sqrt{\sum_{n=2}^{h}\left|V_{n}\right|^{2}}}{\left|V_{1}\right|} \times 100 \% \\
T H D_{I}=\frac{\sqrt{\sum_{n=2}^{h}\left|I_{n}\right|^{2}}}{\left|I_{1}\right|} \times 100 \%
\end{gathered}
$$

(3)

Harmonic distortion has significant effects on distribution equipment and can lead to heating in cables, problems in switching circuitry, malfunctions in control systems; increased costs due to increased maintenance, component failures or devices de-rating and reduced service life of equipment. It has been observed that the net harmonic currents produced by multiple harmonic loads are not strictly additive because there is some naturally occurring phase cancellation [10]. The distortion limit for voltage and current are shown in Tables I and II.

\section{MATERIALS AND METHODS}

The purpose of this study is to quantify the distortion in voltage and/or current waveforms of stabilizer and UPS in a power system application. The need arises as a result of perceived distortion in existing systems due to installation of nonlinear devices or harmonic-producing equipment. Measurements were carried out on the equipment in the laboratory with harmonic-producing loads such as laptops and cathode ray oscilloscope.

The set up for this experimental investigation consists of five laptops each rated at $65 \mathrm{~W}$, two cathode ray oscilloscopes each rated at $42 \mathrm{~W}$, a stabilizer, an UPS, a single phase power supply unit and other accessories such as connecting cables, switches and socket. Measurements were conducted on both the voltage stabilizer and UPS in a laboratory under the same condition. The Century brand stabilizer model with power rating of $1.5 \mathrm{kVA}$ was used for the work while the model of the UPS was $625 \mathrm{~W}$ Mercury type.

TABLE I VOLTAGE DISTORTION LIMIT [11]
\begin{tabular}{|l|l|l|}
\hline Bus voltage, V at PCC & $\begin{array}{l}\text { Individual } \\
\text { harmonic (\%) }\end{array}$ & $\begin{array}{l}\text { Total } \\
\text { harmonic } \\
\text { distortion, } \\
\text { THD (\%) }\end{array}$ \\
\hline $\mathrm{V} \leq 10 \mathrm{kV}$ & 5.0 & 8.0 \\
\hline $1 \mathrm{kV}<\mathrm{V} \leq 69 \mathrm{kV}$ & 3.0 & 5.0 \\
\hline $69 \mathrm{kV}<\mathrm{V} \leq 161 \mathrm{kV}$ & 1.5 & 2.5 \\
\hline $161 \mathrm{kV}<\mathrm{V}$ & 1.0 & 1.5 \\
\hline
\end{tabular}

\begin{tabular}{|c|c|c|c|c|c|c|}
\hline \multirow{2}{*}{\multicolumn{7}{|c|}{$\begin{array}{l}\text { Maximum Harmonic current distortion in per } \\
\text { I }_{L} \\
\text { Individual harmonic order (odd harmonics) })^{\text {a.b }}\end{array}$}} \\
\hline & & & & & & \\
\hline $\mathrm{ISC}_{\mathrm{SC}} / \mathrm{I}_{\mathrm{L}}$ & $\begin{array}{l}3 \leq h \\
<11\end{array}$ & $\begin{array}{l}11 \leq h \\
<17\end{array}$ & $\begin{array}{l}17 \leq h \\
<23\end{array}$ & $\begin{array}{l}23 \leq h \\
<35\end{array}$ & $\begin{array}{l}35 \leq \\
h< \\
50\end{array}$ & TDD \\
\hline$<20^{\mathrm{c}}$ & 4.0 & 2.0 & 1.5 & 0.6 & 0.3 & 5 \\
\hline $\begin{array}{l}20<5 \\
0\end{array}$ & 7.0 & 3.5 & 2.5 & 1.0 & 0.5 & 8 \\
\hline $\begin{array}{l}50<1 \\
00\end{array}$ & 10.0 & 4.5 & 4.0 & 1.5 & 0.7 & 12 \\
\hline $\begin{array}{l}100< \\
1000\end{array}$ & 12.0 & 5.5 & 5.0 & 2.0 & 1.0 & 15 \\
\hline $\begin{array}{l}>100 \\
0\end{array}$ & 15.0 & 7.0 & 6.0 & 2.5 & 1.4 & 20 \\
\hline
\end{tabular}

TABLE II CURRENT DISTORTION LIMIT FOR SYSTEM LESS THAN 69KV [11]

An earlier study shows that the popular brands of UPS common among the commercial users are $A P C$, Blue Gate, $H P$, Mercury and Zinox with Mercury brand perceived as dominant choice among the end-users in the areas of study [12].

The analyser used was Power and Harmonic Analyser DW 6095 model. It can be used for the analysis of single and three-phase system with different wire configurations such as single phase two wires $(1 \mathrm{P} / 2 \mathrm{~W})$, single phase three wires $(1 \mathrm{P} / 3 \mathrm{~W})$, three phase three wires $(3 \mathrm{P} / 3 \mathrm{~W})$ and three phase four wires $(3 \mathrm{P} / 4 \mathrm{~W})$. It can measure different electrical parameters such as voltage (phase-to-phase and phase-toground), current, harmonics display (1-50th order) and power (real, apparent, and reactive) among others [13].

Parameters investigated include the voltage (including peak-peak value), current, frequency, harmonic distortion and crest factor. Similar study had been carried out in residential areas for the purpose of monitoring the power quality in the distribution network [13]. The power quality of distribution 
systems has a drastic effect on power regulation and consumption. Power sources act as nonlinear loads, drawing a distorted waveform that contains harmonics. These harmonics can cause problems ranging from telephone transmission interference to degradation of conductors and insulating material in motors and transformers. Total harmonic voltage distortion (THDv) and Total harmonic current distortion (THDi) are the measure of distortion in the system. When the THDv is less than $5 \%$, this is taken as normal situation with no risk of malfunctions. When it is from 5 to $8 \%$, then it implies significant harmonic pollution and some malfunctions are possible. However, when it is higher than $8 \%$, it means that there is a major harmonic pollution and malfunctions are probable. In such a situation an in-depth analysis and the installation of attenuation devices are required [14]. Crest factor is used to characterise the amplitude of a generator (or UPS) to supply high instantaneous currents.

Measurements were conducted on both the voltage stabilizer and UPS in a laboratory under the same condition. The power rating of the stabilizer used is $1.5 \mathrm{kVA}$ while that of the UPS is $625 \mathrm{~W}$. The analyser used was Power and Harmonic Analyser DW 6095 model. Each of the devices under test (Stabilizer and UPS) was loaded in turn with laptops $(65 \mathrm{~W})$ and two cathode ray oscilloscopes (42 W each). The loads were added sequentially and readings recorded. The set-up was as shown in Fig. 1

\section{M RESULTS AND DISCUSSION}

Tables III and IV show the summary of the readings from stabilizer and UPS respectively. Though all the waveforms were recorded only some of them are shown because of space constraints. Figs. 2 and 3 show the recorded waveforms from the stabilizer while Figs. 4 and 5 show the corresponding waveforms for the UPS.

The results obtained for the power quality measurement are as shown in Tables III and IV for the voltage stabilizer and the UPS respectively. Table $\mathrm{V}$ gives a comparison of the results for the voltage stabilizer and the UPS. Further, a plot of the voltage output for the stabilizer against that of the UPS was obtained and given in Fig. 6. The graphs of the current output, percentage THD, peak-to-peak voltage frequency and the crest factor are given on Figs. 7-11 respectively.

Table V shows the summary of the readings for the two equipment. Compared to the normal standard both equipment show varying degree of compliant and non-compliant. For voltage, frequency, and crest factor, they fall within the expected ranges. Current and peak-peak voltage are functions of loads and applied voltage. However, the THD in both devices shows high departure from the standard. The least values of $10.6 \%$.

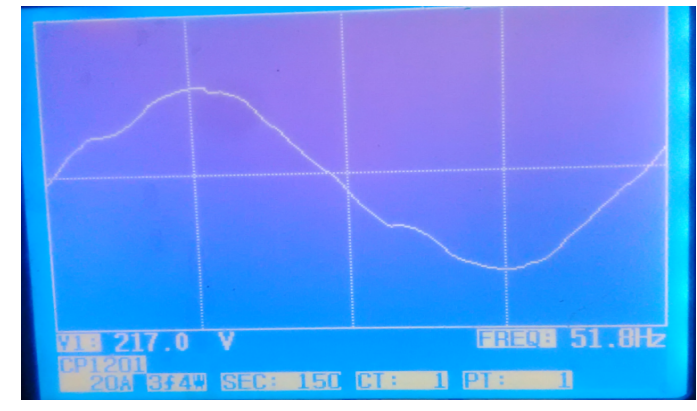

Fig.2 Voltage waveform for a laptop

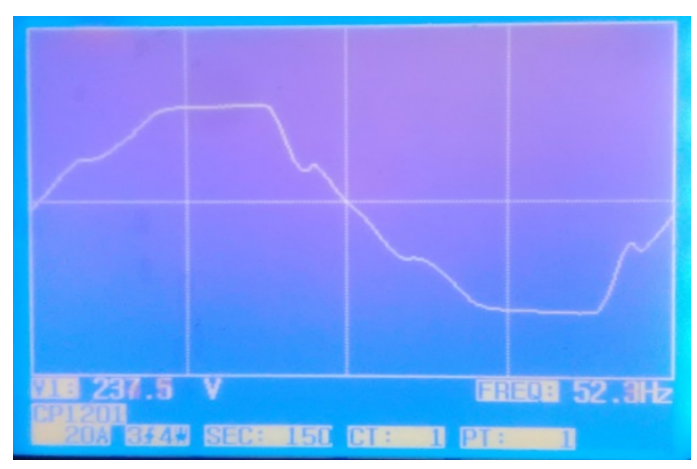

Fig. 3 Voltage waveform for five laptops and two oscilloscopes

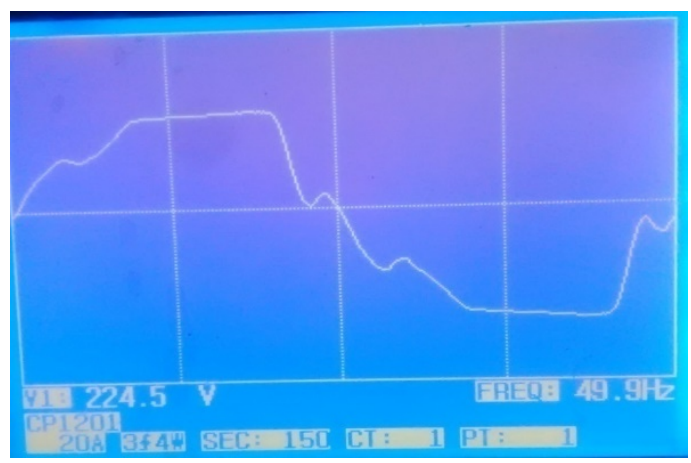

Fig. 4 Voltage waveform for a Laptop

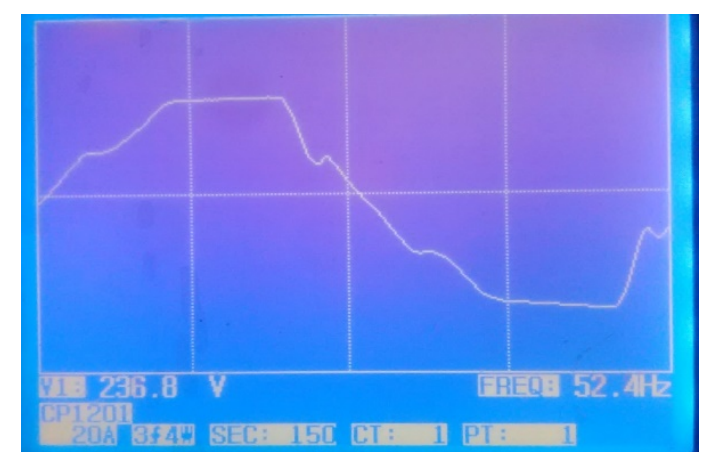

Fig. 5 Voltage waveform for five laptops and two oscilloscope 


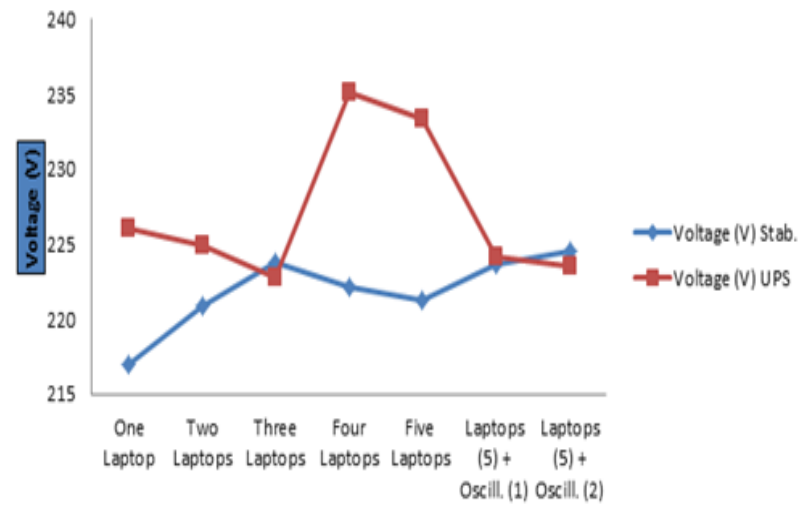

Fig. 6 Voltage output

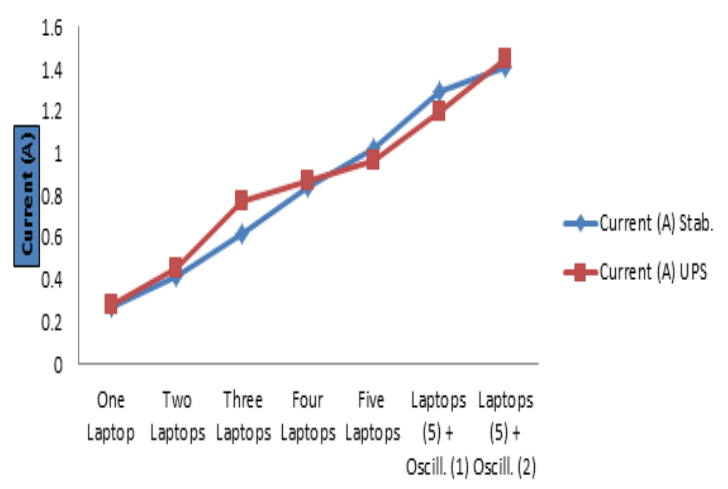

Fig. 7 Current output

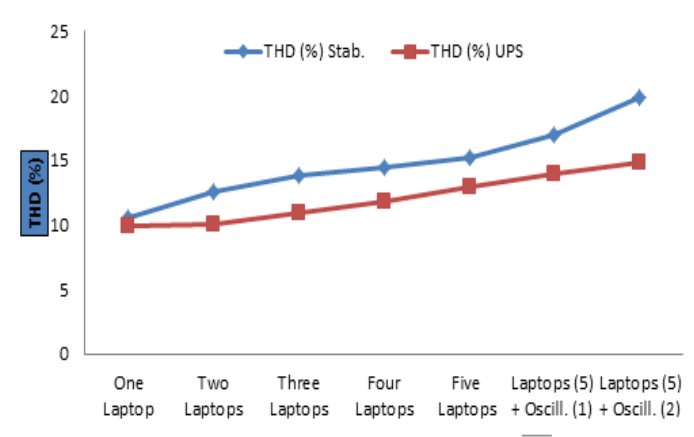

Fig. 8 Percentage THD

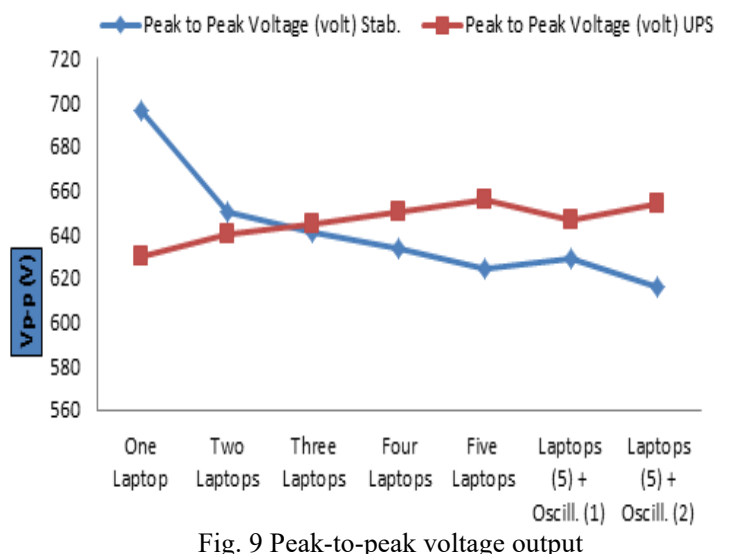

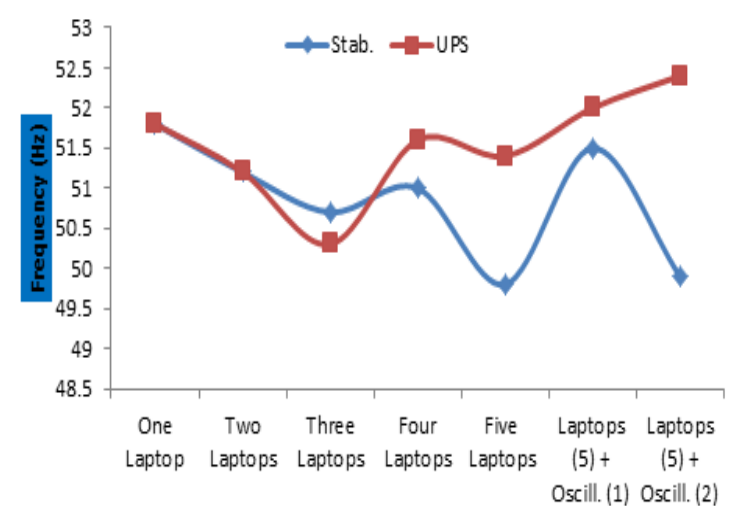

Fig. 10 Frequency output

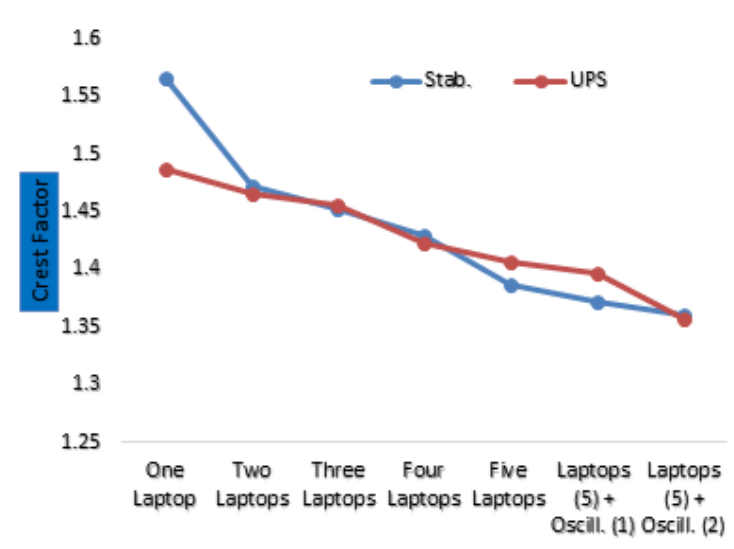

Fig. 11: Crest factor

and $9.9 \%$ for the stabilizer and the UPS respectively are higher than the recommended value of 5\% for total voltage distortion.

This means that there is a potential for major harmonic pollution and malfunctions in the system. Both the stabilizer and the UPS show similar pattern in most of the readings. Though the outputs from UPS are relatively higher than that of stabilizer except for some instances where that of stabilizer were higher; there is no significant difference between their values on the average. With the total harmonic distortion produced in voltage stabilizer greater than that of the UPS as shown in the results, the stabilizer contributes more to the harmonic pollution than UPS. Harmonic distortion can have detrimental effects on electrical equipment. These unwanted and unwarranted distortions are increasing the current in power systems which can results in higher temperatures in the devices. More often than not, their harmful effect goes unnoticed until an actual failure occurs. Perhaps, this may be contributing to incessant failure of these devices.

A similar study earlier carried out in a residential building revealed violation of standard by voltage variation while the harmonic was within the standard [13]. In that study, the output was measured directly from the main power source without any conditioning device. Thus the effects of power conditioning devices were clearly seen. While the voltage and frequency were within the standard (due to operational design), the electronic nonlinear devices nature of these devices contributed to the high distortion. However, other linear loads which were usually with higher rating often suppressed the distortion effects in the distribution system.

Also, the results for both devices confirm that the net THD is not additive due to harmonic cancellation effect [10]. 
TABLE III EXPERIMENTAL RESULT FOR THE VOLTAGE STABILIZER

\begin{tabular}{|l|l|l|l|l|l|l|l|}
\hline & $\begin{array}{l}\text { Equipment } \\
\text { connected to } \\
\text { stabilizer }\end{array}$ & $\begin{array}{l}\text { Voltage } \\
\text { (V) }\end{array}$ & $\begin{array}{l}\text { Current } \\
\text { (A) }\end{array}$ & $\begin{array}{l}\text { Frequency } \\
\text { (Hz) }\end{array}$ & $\begin{array}{l}\text { Peak to } \\
\text { peak } \\
\text { voltage } \\
\text { (volt) }\end{array}$ & $\begin{array}{l}\text { Total } \\
\text { harmonic } \\
\text { distortion } \\
\text { (\%) }\end{array}$ & Crest factor \\
\hline $\mathbf{1}$ & 1 laptop & 217.0 & 0.271 & 51.8 & 696.1 & 10.6 & 1.566 \\
\hline $\mathbf{2}$ & 2 laptops & 220.9 & 0.418 & 51.2 & 650.1 & 12.6 & 1.472 \\
\hline $\mathbf{3}$ & 3 laptops & 223.8 & 0.616 & 50.7 & 640.5 & 13.8 & 1.452 \\
\hline $\mathbf{4}$ & 4 laptops & 222.1 & 0.842 & 51.0 & 633.3 & 14.4 & 1.429 \\
\hline $\mathbf{5}$ & 5 laptops & 221.2 & 1.023 & 49.8 & 624.1 & 15.2 & 1.386 \\
\hline $\mathbf{6}$ & $\begin{array}{l}\text { 5 laptops }+1 \\
\text { oscilloscope }\end{array}$ & 223.7 & 1.295 & 51.5 & 628.7 & 17 & 1.372 \\
\hline $\mathbf{7}$ & $\begin{array}{l}\text { 5 laptops + } \\
\text { oscilloscopes }\end{array}$ & 224.5 & 1.411 & 49.9 & 615.9 & 19.9 & 1.360 \\
\hline
\end{tabular}

TABLE IV EXPERIMENTAL RESULT FOR THE UPS

\begin{tabular}{|l|l|l|l|l|l|l|l|}
\hline & $\begin{array}{l}\text { Equipment connected } \\
\text { to UPS }\end{array}$ & $\begin{array}{l}\text { Voltage } \\
\text { (V) }\end{array}$ & $\begin{array}{l}\text { Current } \\
\text { (A) }\end{array}$ & $\begin{array}{l}\text { Frequency } \\
\text { (Hz) }\end{array}$ & $\begin{array}{l}\text { Peak to } \\
\text { peak } \\
\text { voltage } \\
\text { (V) }\end{array}$ & $\begin{array}{l}\text { Total } \\
\text { harmonic } \\
\text { distortion } \\
\text { (\%) }\end{array}$ & $\begin{array}{l}\text { Crest } \\
\text { factor }\end{array}$ \\
\hline $\mathbf{1}$ & 1 laptop & 226.0 & 0.276 & 51.8 & 630 & 9.9 & 1.487 \\
\hline $\mathbf{2}$ & 2 laptops & 224.9 & 0.454 & 51.2 & 640 & 10.1 & 1.466 \\
\hline $\mathbf{3}$ & 3 laptops & 222.8 & 0.774 & 50.3 & 645 & 10.9 & 1.456 \\
\hline $\mathbf{4}$ & 4 laptops & 235.1 & 0.872 & 51.6 & 650 & 11.8 & 1.423 \\
\hline $\mathbf{5}$ & 5 laptops & 233.4 & 0.967 & 51.4 & 656 & 12.9 & 1.407 \\
\hline $\mathbf{6}$ & $\begin{array}{l}\text { 5 laptops + } \\
\text { oscilloscope }\end{array}$ & 224.2 & 1.193 & 52 & 646.5 & 13.9 & 1.396 \\
\hline $\mathbf{7}$ & $\begin{array}{l}\text { 5 laptops + } \\
\text { oscilloscopes }\end{array}$ & 223.5 & 1.447 & 52.4 & 653.9 & 14.8 & 1.357 \\
\hline
\end{tabular}

TABLE V COMPARISON BETWEEN THE STABILIZER AND THE UPS

\begin{tabular}{|l|l|l|l|l|l|l|l|l|}
\hline Equipment & \multicolumn{2}{|l|}{ Voltage (V) } & \multicolumn{2}{l|}{ Current (A) } & \multicolumn{2}{l|}{ THD (\%) } & \multicolumn{2}{l|}{ Crest Factor } \\
\hline & Stab. & UPS & Stab. & UPS & Stab. & UPS & Stab. & UPS \\
\hline One Laptop & 217.0 & 226.0 & 0.271 & 0.276 & 10.6 & 9.9 & 1.566 & 1.487 \\
\hline Two Laptops & 220.9 & 224.9 & 0.418 & 0.454 & 12.6 & 10.1 & 1.472 & 1.466 \\
\hline Three Laptops & 223.8 & 222.8 & 0.616 & 0.774 & 13.8 & 10.9 & 1.452 & 1.456 \\
\hline Four Laptops & 222.1 & 235.1 & 0.842 & 0.872 & 14.4 & 11.8 & 1.429 & 1.423 \\
\hline Five Laptops & 221.2 & 233.4 & 1.023 & 0.967 & 15.2 & 12.9 & 1.386 & 1.407 \\
\hline Laptops (5) + Oscill. (1) & 223.7 & 224.2 & 1.295 & 1.193 & 17.0 & 13.9 & 1.372 & 1.396 \\
\hline Laptops (5) + Oscill. (2) & 224.5 & 223.5 & 1.411 & 1.447 & 19.9 & 14.8 & 1.360 & 1.357 \\
\hline
\end{tabular}


Otherwise with the values of $10.6 \%$ and $9.9 \%$ for a single laptop in the stabilizer and the UPS readings, the net THD would have been $53 \%$ and $49.5 \%$ respectively.

\section{CONCLUSIONS}

Voltage stabilizer and UPS are popular indispensable equipment especially for sensitive electronic devices. Their popularity soars because of poor power supply. However, little attention is paid to their impact on the distribution network. This research attempts to examine the impact of these common nonlinear devices on power supply. This becomes necessary as a result of growing demands for these devices Nigerian power network is no doubt a weak one. The ability of such weak network to handle large influx of harmonic producing devices needs proper evaluation so as not to worsen the situation. The findings show that these devices are increasing potential threat to electrical network. This research can be useful for the stakeholders in power industry for power quality improvement.

As a way of mitigating the impact of these nonlinear devices, the following recommendations are necessary to enhance a quality delivery of electrical power services:

- $\quad$ There is need to strengthen the local regulation to capture the impact of growing nonlinear devices within the distribution network.

- The standard organization of Nigeria should ensure that both imported and locally manufactured voltage stabilizers and UPS conform to the required standards.

- Enlightenment campaign should be carried out among the end-users on proper usage of power conditioning devices.

- $\quad$ Moreover, comprehensive studies are needed for indepth analysis before installation of attenuation devices.

\section{REFERENCES}

[1] S. V. D. A. Kumar and K. R. Reddy, Computation of the Power Flow Solution of a Radial Distribution System for Harmonic Components. Int. J. Energy, Info. Commun. vol. 4 (1), February, 2013.

[2] S. J. Ranade and W. Xu, "An Overview of Harmonic Modelling and Simulation, Tutorial Harmonics Modeling and Simulation", IEEE Power Engineering Society, 1998.

[3] O. Arobieke, S. Osafehinti, F. Oluwajobi and O. Oni, "Electrical Power Outage in Nigeria: History, Causes and Possible Solutions", J. Energy Technol. Policy, Vol. 2, No. 2, pp. 18-23, 2012.

[4] D. Robinson, S. Perera, V. Gosbell and V. Smith, "Voltage Fluctuations in the Electric Supply System", Technical Note, No. 7, The Integral Energy Power Quality Centre, School of Electrical, Computer and Telecommunications Engineering, University of Wollongong, Australia, 2003.

[5] R. B. Standler, "Protection of Electronic Circuit from OverVoltage", $2^{\text {nd }}$ ed., University of Queensland Press, pp. 36-38., 1989.

[6] M. F. McGranaGhan, D. R. Mueller and M. J. Samotyj, "Voltage Sags in Industrial Systems", IEEE Trans. on Ind, Appl., vol. 29, pp. 397-403, 1993

[7] R. C. Dugan, M. F. McGranaghan and H. W. Beaty, "Electrical Power Systems Quality, McGraw-Hill, New York, pp. 172-174, 1996.

[8] E. Möllerstedt, "Dynamic Analysis of Harmonics in Electrical Systems", PhD thesis Department of Automatic Control, Lund Institute of Technology (LTH), 2000.
[9] A. Ogunlade, "Utilization of Electronic Equipment", $1^{\text {st }}$ ed., Omolayo Standard Press, Ado-Ekiti, p. 6, 1999

[10] M. Grady, "Understanding Power System Harmonics", University of Texas. https://web.ecs.baylor.edu/faculty/grady/Understanding_Power_S ystem Harmonics Grady_April 2012.pdf Retrieved 15 July 2017.

[11] IEEE Std. 519 ${ }^{\mathrm{TM}}-2014$, IEEE Recommended Practice and Requirements for Harmonic Control in Electric Power Systems.

[12] J. Ogunyemi and I. A. Adejumobi, "Performance Evaluation of Power Quality Mitigating Equipment: A Case Study of Uninterrupted Power Supply (UPS) Applications in Ilaro", Int. J. Eng. Res. Tech. vol. 2 (12), December 2013.

[13] J. Ogunyemi and I. A. Adejumobi, Improving Power Quality in Residential Area of Distribution Network through Monitoring. Paper presented at Nigerian Society of Engineers' National Conference, Exhibition and Annual General Meeting, Akure Nigeria, $16^{\text {th }}-20^{\text {th }}$, November 2015 .

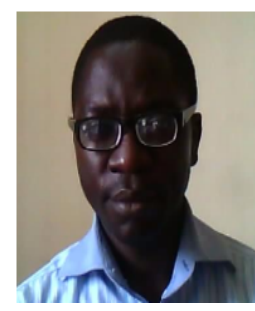

Joel Ogunyemi is a graduate of University of Ilorin and University of Lagos, both in Nigeria, where he obtained his B. Eng. (Electrical Engineering) and MSc. (Electrical/Electronic Engineering) respectively with specialization in Instrumentation and Control Engineering. His research areas include Power Measurement, Power Quality, Energy management/audit. He had working experience in manufacturing industries before joining the academia. Presently, he is a lecturer in the Department of Electrical/Electronic Engineering, The Federal Polytechnic Ilaro. He is a Corporate member of the Nigerian Society of Engineers and Council for the regulation of engineering in Nigeria (COREN) registered.

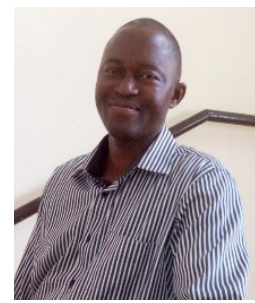

Zacchaeus A. Adetona obtained a B.Sc. in Electronic and Electrical Engineering from Obafemi Awolowo University, Ile-Ife, Osun State, Nigeria. He has also obtained a M. Eng. degree in Electronic Control Engineering at the Federal University of Agriculture, Abeokuta, Ogun State, Nigeria. He previously worked with The Department of Electrical/Electronic Engineering, Lagos City Polytechnic, Ikeja as Assistant Lecturer. He currently works as a lecturer at Department of Electrical/Electronic Engineering, The Federal Polytechnic, Ilaro, Nigeria where he serves as the departmental Research and Development Personnel. His research interests include renewable energy systems, energy efficiency, instrumentation and control devices for power distribution and embedded system control. $\mathrm{He}$ is a Corporate member of the Nigerian Society of Engineers and registered with the Council for the regulation of engineering in Nigeria (COREN). 